\title{
Connecting the dots: social network structure, conflict, and group cognitive complexity
}

\author{
Petru L. Curşeu • Steffie E. A. Janssen · Jörg Raab
}

Published online: 29 June 2011

(c) The Author(s) 2011. This article is published with open access at Springerlink.com

\begin{abstract}
The current paper combines arguments from the social capital and group cognition literature to explain two different processes through which communication network structures and intra group conflict influence groups' cognitive complexity (GCC). We test in a sample of 44 groups the mediating role of intra group conflict in the relationship between communication network density and fragmentation on the one hand and groups' cognitive complexity on the other hand. The results show that network fragmentation has a positive effect on GCC by fostering task conflict, while network density has a positive impact on GCC by reducing relationship conflict in student groups. The paper makes an important contribution to both theory and practice in the field of collaborative learning, by exploring how groups' affective and a cognitive dynamics impact on emergent collective cognitive structures.
\end{abstract}

Keywords Group cognitive complexity · Collaborative learning · Communication networks - Task and relationship conflict

\section{Introduction}

Modern organizations heavily rely on teamwork to accomplish a variety of tasks ranging from production to strategic decisions (Devine 2002), and teamwork skills become a valuable asset for employees in most industries (Burch and Anderson 2004). Higher education institutions have responded to this trend and extensively use group project work (collaborative and cooperative learning) as a pedagogical tool (Davies 2009; Graen et al. 2006). Task division in collaborative learning involves a high degree of interdependence and task accomplishment requires effective coordination and mutual engagement of students (Dillenbourg et al. 1996). As students from a variety of disciplines are often involved

P. L. Curşeu (凹) · S. E. A. Janssen - J. Raab Department of Organisation Studies, Tilburg University, Room, P1.161; Warandelaan 2, PO Box 90153, Tilburg 5000 LE, The Netherlands e-mail: P.L.Curseu@uvt.nl 
in group work and group dynamics is essential for collaborative learning, it becomes increasingly important to understand the factors that influence the effectiveness of collaborative learning both at the individual as well as group level (Cohen 1994). While the individual gains of collaborative and cooperative learning are well investigated (Davies 2009; Lizzio and Wilson 2006; Springer et al. 1999), the effects of collaborative learning at the group level of analysis have not been extensively addressed (Haggis 2009). Research on how student groups (as socio-cognitive systems) learn in classroom settings is rather disconnected from the research insights on group cognition and group learning in the organizational behavior literature. We address this gap by testing the effect of social structure (the pattern of interpersonal communication in small student groups), and team conflict on group cognitive complexity. In order to do so, we combine insights from social networks and group cognition approaches to argue that intra-group conflict mediates the impact of social network structure on group cognitive complexity.

Small groups are socio-cognitive systems (Driver and Streufert 1969; Hinsz et al. 1997) and the way they process information depends both on the cognitive processes and representations of the individual group members and on the interpersonal interactions between them (Curşeu and Schruijer 2008; Curşeu et al. 2010). Group cognitive complexity (GCC) refers to the richness of collective knowledge structures emerging from knowledge exchange through interpersonal interaction within a team (Curşeu et al. 2007). A complex cognitive structure emerging from interpersonal interactions in groups is both differentiated (includes many semantic nodes, concepts or themes) and integrated (the nodes are richly interconnected) (Curşeu et al. 2010; Driver and Streufert 1969). In order to produce highly differentiated cognitive structures group members have to contribute with their unique and diverse (sometimes conflicting) knowledge to the group debates (Curşeu et al. in press) or in other words they have to engage in task related conflicts. However, in order to achieve integration, they have to solve these disagreements in an amiable fashion. The quality of interpersonal interaction is therefore a key driver of emergent collective cognitive structures.

As argued before, interacting teams often experience conflicts (Parayitam and Dooley 2009), either in the form of task related disagreements or interpersonal frictions (Jehn 1995). Task conflict refers to the disagreements about task content and has also been labeled cognitive conflict (it involves conflicting ideas, points of view), while relationship conflict is mostly emotional in nature because it involves disagreements about (inter)personal issues (Pinkley 1990). The interplay between affect and cognition delineates the conditions under which conflict is beneficial or detrimental for group outcomes. Because relationship conflict is closely associated with negative emotionality, it often diminishes team performance, while task conflict might also have positive outcomes because it fosters the cognitive activity of the group (e.g., information search and information evaluation) (Curşeu and Schruijer 2010; Jehn 1994, 1995). With respect to group cognitive complexity, we posit that task conflict enhances the complexity of a group's collective knowledge representations because it is associated with various opinions expressed during group discussions (Simons and Peterson 2000), which yield superior outcomes as compared to individual cognitive efforts (Amason 1996, p. 127). Relationship conflict on the other hand, will lead to lower cognitive complexity of the group because it is associated with stress and anxiety, which decrease the cognitive flexibility and the ability to consider alternative perspectives, which will ultimately narrow groups' cognitive repertoire (Carnevale and Probst 1998; Jehn and Mannix 1997). Therefore, the first two hypotheses of this study are: 
Hypothesis 1 Task conflict has a positive direct effect on a groups' cognitive complexity.

Hypothesis 2 Relationship conflict has a negative direct effect on a groups' cognitive complexity.

Previous studies have found that task and relationship conflict are highly correlated, in such a way that high task conflict may trigger relationship conflict (Curşeu and Schruijer 2010; Simons and Peterson 2000). In other words, when task related disagreements trigger emotional reactions, task conflict develops into relationship conflict and is likely to be detrimental for GCC. Therefore, in addition to the hypothesized direct effects, our third hypothesis states:

Hypothesis 3 The negative relationship between task conflict and a group's cognitive complexity is explained by relationship conflict.

The interplay among cognitive dissent (task conflict) and social harmony (lack of relationship conflict) depends on the pattern of communication between group members (Curşeu et al. in press). In line with a social capital argument, information resources that become available to a group through the configuration of group members' social relationships and communication networks are essential for group effectiveness in information processing (Oh et al. 2004). Two approaches have dominated the debate about the most optimal structure for the information-processing abilities of teams, namely the bonding and bridging social capital approaches. The former approach stresses the affective benefits of dense social networks and argues that full connectedness is beneficial for performance because it is associated with high levels of trust (Coleman 1988) and identification with the group (Portes and Sensenbrenner 1993). Groups with fully connected communication networks experience a positive emotional climate, which fosters information sharing, information elaboration and ultimately increases group performance. The latter approach in contrast uses more cognitive arguments, emphasizing that ties to people who possess different resources and express different points of view are beneficial, because these ties provide group members with non-redundant information and thus foster cognitive differentiation (Burt 1992). In sum, the insights from the social capital literature distinguish between an affective and a cognitive process tied to information exchange in small groups.

The affective path is related to connectedness and the core argument is that social network density facilitates social integration and social harmony. Density can be defined as "the general level of linkage among the points in a graph" (Scott 1991, p. 69) and is positively related to cohesiveness and trust within a team (Oh et al. 2004; Reagans et al. 2004). This assertion dates back to the classic work of Coleman (1988), who has argued that in fully connected social networks, collective sanctions can be established and as a result trustworthiness and cohesiveness will emerge. Previous research on intra-group trust shows that when levels of trust are high, group members are less likely to interpret ambiguous behavior of group members negatively (Simons and Peterson 2000) and to feel attacked by arguments made by others (Curşeu and Schruijer 2010), thus they are less likely to experience relationship conflict. Dense network structures are therefore likely to reduce the likelihood of relationship conflict.

In addition to the affective processes associated with social network density, we argue that network structure can also trigger cognitive (task) conflict within teams. Within the social capital literature, it has been argued that opinions and behaviors are often accumulated within densely connected parts of a social network (i.e., cliques) (Burt 2005). This is a result of the fact that clique members are more likely to communicate and share information within their own clique than across cliques (Burt 2005). A team consisting of 
many cliques will therefore have differentiated information, which will trigger disagreement about task content, or in other words, task conflict. We thus hypothesize that:

Hypothesis 4 Network density has a negative direct effect on relationship conflict.

Hypothesis 5 Network fragmentation (the number of cliques) has a positive direct effect on task conflict.

Hypothesis 6 The impact of network density and network fragmentation on GCC is fully mediated by task and relationship conflict.

\section{Methods}

Sample

A sample of 210 students (113 women), ranging in age from 20 to 38 (average 23.55) participated in the study. All participants were enrolled in a Masters course at a Dutch university and they were grouped in 44 teams having 3-7 members (average 4.8). The course consisted mainly of workshops, in which the student teams worked with the course material by analyzing case studies and discussing their findings. The task of all of the groups was to collaboratively write a research paper on a topic of their choice. The final paper was graded, and the grade covered $60 \%$ of the overall grade for the course.

\section{Procedure}

We used a cognitive (conceptual) mapping technique (Davies, in press) to measure group cognitive complexity. This method is a holistic evaluation method for group cognition because it evaluates the knowledge structures as they emerge from interpersonal interactions (Curşeu et al. 2010). In the final workshop of the course all groups were asked to analyze a set of concepts about intra-organizational complexity by creating a cognitive map. All groups received an envelope with 20 concepts, a sheet of paper and glue. The groups were asked to organize the concepts in such a way that the spatial proximity reflected the extent to which the concepts were related. Moreover, groups had to specify the nature of the relationships between the concepts. The final conceptual map created by the groups was used to compute the group's cognitive complexity. Three indicators were used in this computation: (1) the number of connections established between concepts, (2) map diversity was used as an indicator for the number of distinct relations established between the concepts and (3) the number of concepts used in the map was counted. Seven distinct types of relationships were considered, based on the taxonomy suggested by Gómez et al. (2000): causal, association, equivalence, topological, structural, chronological, and hierarchical relations. The following formula was then used to compute the cognitive complexity of a group (connectivity*diversity)/number of concepts (Curşeu et al. 2010). The more distinct relations and connections established relative to the number of concepts, the higher the complexity of the conceptual map.

In addition to this conceptual mapping procedure, all students filled out a questionnaire (an English version was used since several international students were enrolled in the program) in which they answered several questions about the communication patterns within groups and about the intra group conflicts. Answers to these questions were used to compute our social network and conflict variables, each of which will be described below. 
Network fragmentation was measured by asking students to evaluate the frequency of communication with their teammates regarding their work on the team project. The evaluations ranged from -5 "extremely rare communication" to +5 "very frequent communication". Network fragmentation was computed as the number of cliques, the scores were recoded to values ranging from 1 to 11 and then dichotomized, so that scores lower than 6 indicated the absence, and scores of 6 or higher indicated the presence of a relationship. The number of cliques was then computed using UCINET, version 6.0 (Borgatti et al. 1992).

Network density was calculated using UCINET. The same question in which students indicated their frequency of communication with team members was used. We again used the recoded data, however, we did not dichotomize the scores for this measure (Scott 1991). The final density score was computed by dividing the total of all values by the number of possible ties.

Task conflict was measured using four items from an intra-group conflict scale originally introduced by Jehn (1995). Examples of items are: "to what extent are there differences of opinion in your team?" and "to what extent are disagreements in your team related to the task?". The items were recorded on a 5 point Likert scale (from $1=$ to a little extent to $5=$ to a very large extent) and Cronbach's alpha was .74.

Relationship conflict was evaluated using four items from the intra-group conflict scale (Jehn 1995). Examples of items are: "how often are personality conflicts evident in your team?" and "how often do people get angry while working in your team?". The items were also recorded on a 5 point Likert scale (from $1=$ rarely to $5=$ very often) and Cronbach's alpha for this scale was .78. Individual scores for task and relationship conflict were aggregated to the group level. The Rwg scores (the within group agreement index reflects the extent to which members within the same group agree in their evaluation of within group conflict) are all higher than .78 , showing a high degree of within group agreement and supporting group level aggregation.

\section{Results}

The analysis was conducted using AMOS structural equation modeling (SEM) software, version 18. This technique makes it possible to estimate global fit indices for complex mediation models in which several (mediator) variables are simultaneously used (Tomarken and Waller 2005). The model fit summary is presented in Fig. 1. We used two categories of fit indices: absolute fit indices which illustrate the general fit of the model and incremental fit indices which compare the tested model with the saturated, null model (Widman and Thomson 2003). The overall chi-square value of the model shows a good fit of the model to the data, $\chi^{2}=.952(d f=2), p=.621$. According to the NFI value, the model cannot be significantly improved, $N F I=.983$. In addition, the root mean square error of approximation was much lower $(R M S E A=.0001)$ than the .08 which is recommended for a good model fit (Brown and Cudeck 1993). We can thus conclude that the implied variances and covariances match the observed variances and covariances in the data.

The results of the path analysis are presented in Fig. 1. We hypothesized a positive relationship between task conflict and group cognitive complexity, while for relationship conflict a negative relationship was expected. The analysis showed that both relationships were in the expected direction, although they only reached marginal statistical significance. In hypothesis 3, we expected a positive relationship between task and relationship conflict, 
Results of the path analysis for the overall model

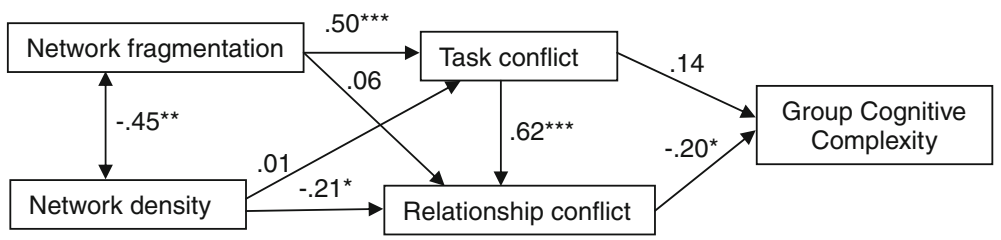

Fig. 1 Results of the path analysis for the overall model. Notes: Standardized path coefficients are presented in the figure, fit indices: $C M I N=.952, d f=2, p=.621 C F I=1.000, N F I=.983, T L I=1.189$, $R M S E A=.0001 ; * p<.10, * * p<.05, * * * p<.001$

in such a way that task conflict would also have an influence on group cognitive complexity via relationship conflict. We found strong support for this hypothesis, as illustrated by the standardized path coefficient presented in Fig. 1. The final three hypotheses were about the effects of the social network variables on team conflict. The expected negative effect of network density on relationship conflict (Hypothesis 4) is fully supported by the data. The results also support Hypothesis 5, which predicted a positive effect of the number of cliques on task conflict. Finally, the general mediation hypothesis stating that the impact of network density and network fragmentation on GCC is mediated by task and relationship conflict was fully supported as shown by the incremental and absolute fit indices of our tested model.

\section{Discussion}

This paper sheds new light on the antecedents of intra-group conflict and cognitive complexity in student teams by taking a social capital perspective. We argued that the impact of social network structure on group cognition is explained by two mechanisms: a cognitive activation path (associated with task conflict) and a negative affectivity path (associated with relationship conflict). Our results support these claims and show that different social network structures trigger different types of conflicts within teams, a finding that should be taken into account when designing student teams. We have shown that dense networks lower the level of relationship conflict and as a result enhance group cognitive complexity. This negative impact of relationship conflict on group cognitive complexity is attributable to the negative emotional climate associated with relationship conflict. Previous research shows that negative emotionality decreases the cognitive flexibility of the group members, their motivation to actively seek new information and to explore various alternatives (Carnevale and Probst 1998) and as a consequence leads to more rigid and less complex cognitive structures both at the individual and the group level. In classroom settings, relationship conflict needs to be properly managed in order to make collaborative learning more effective. Dense communication networks are likely to decrease relationship conflict, therefore educators should strive for social integration and stimulate frequent interpersonal interactions in student groups. Previous research also stresses the importance of trust-building in reducing the levels of conflict within a team (Curşeu and Schruijer 2010; Simons and Peterson 2000), therefore a trusting group climate could be a very effective way of managing intra-group conflicts.

In addition to the detrimental effects of relationship conflict, we have found evidence for a positive impact of task conflict on learning in student teams (a cognitive activation 
effect). Our results show that teams consisting of more cliques experienced higher task conflict which in turn leads to higher cognitive complexity. This set of findings shows considerable similarities with the technique of dialectical inquiry used in decision making, in which the group is divided in two subgroups (cliques in social networks terms); one subgroup should develop a plan, another subgroup a counter-plan, and finally these different views should be discussed and integrated into a comprehensive decision (Cosier and Rechner 1985). In line with the insights from Davies's (2009) review, our results suggest that it is useful to divide the main group task into interdependent subtasks attributed to subgroups and then upon completion reintegrated them into the final group product.

This study opens several possible directions for future research in the area of collaborative learning. First, it has been argued by Kember (2009) that two important capabilities that can be developed through collaborative learning are communication and interpersonal skills. Communication skills focus on the effective communication of ideas to others and the ability to hold productive dialogues (Kember 2009, p. 49). Interpersonal skills on the other hand are needed for the effective functioning of teams. Our study extends this individualistic view and argues that the benefits of collaborative learning should also be investigated at the group level and issues like group learning and group information processing should receive more attention in future studies on collaborative learning.

The results reported here also support Davies's (2009) argument that the most effective task division is achieved in the additive or conjunctive task structures (Steiner 1972). This recommendation has a clear connection with the cognitive activation path identified within our study. When team members (or subgroups) work on different parts of the task and are dependent on each other for the completion of the overall task, they will discuss their work with one another and the group's cognitive performance will increase as a result of these debates. We wonder however, whether the same recommendation (i.e., additive or conjunctive task division) will also be beneficial for densely connected teams and the associated affective processes. An important reason for Davies (2009) to recommend additive instead of for example disjunctive (performance is dependent on the performance of the best group member) or discretionary tasks is that the final two are much more likely to result in free-riding behavior. Within densely connected teams, however, free-riding is kept in check, since collective sanctioning can take place when a group member does not behave in line with the collective interest. This structure might therefore be very useful for types of tasks carrying the potential for free-riding behavior. If future research finds evidence for this connection between task type and team structure, this might have important implications for practice. The collaborative learning literature emphasizes that tasks assigned to student groups should be designed in order to stimulate interdependence and interaction. Instead of the now often made recommendation to adapt the task type to the nature of teamwork expected, one could instead adapt (i.e., by using normative interventions) the structure of the team to the type of the task.

To conclude, the current study has shown that the structure of interpersonal interactions in student groups impacts on the emergence of intra-group conflict and in order to effectively manage intra-group conflicts, educators should try to reinforce a particular interpersonal interaction structure. Future research should investigate the way in which the interplay between intra-group conflict and social network structure is influenced by variables such as the nature of the task or the type of skills that should be developed through collaborative learning. Based on the high correlation between task and relationship conflict, one general recommendation can be made however: because too many cliques will eventually result in high task conflict and as a result of this also in high relationship 
conflict, a general advice for educators would be to keep the number of cliques moderately high.

A limitation of the current study is the small sample size that might also account for the fact that the relationships between intra-group conflict and cognitive complexity did not fully reach statistical significance. We would like to stress however, that these effects should certainly not be underestimated, because the standardized effect sizes were moderately large. Nevertheless, future research should replicate these results using larger samples. Furthermore, the cross-sectional nature of this study limits the validity of the causality claims for the relationships found. Finally, with regard to the cognitive mapping technique, it may be the case that the structure of the maps is induced by the explicit instructions students received and especially the instruction to reach consensus on the type of conceptual relationships, which remains a boundary condition of our study.

Open Access This article is distributed under the terms of the Creative Commons Attribution Noncommercial License which permits any noncommercial use, distribution, and reproduction in any medium, provided the original author(s) and source are credited.

\section{References}

Amason, A. C. (1996). Distinguishing the effects of functional and dysfunctional conflict on strategic decision making: Resolving a paradox for top management teams. Academy of Management Journal, 39, 123-148. doi:10.2307/256633.

Borgatti, S., Everett, M., \& Freeman, L. (1992). UCINET 6 for Windows: Analytic Technologies.

Brown, M. W., \& Cudeck, R. (1993). Alternative ways of assessing model fit. In K. A. Bollen \& J. S. Long (Eds.), Testing structural equation models (pp. 136-162). Newbury Park, CA: Sage.

Burch, G. S. J., \& Anderson, N. (2004). Measuring person-team fit: Development and validation of the team selection inventory. Journal of Managerial Psychology, 19, 406-426. doi:10.1108/02683940410537954.

Burt, R. S. (1992). Structural holes: The social structure of competition. Cambridge: Harvard University Press.

Burt, R. S. (2005). Brokerage and closure: An introduction to social capital. Oxford: Oxford University Press.

Carnevale, P. J., \& Probst, T. M. (1998). Social values and social conflict in creative problem solving and categorization. Journal of Personality and Social Psychology, 74, 1300-1309. doi:10.1037/00223514.74.5.1300.

Cohen, E. G. (1994). Restructuring the classroom: Conditions for productive small groups. Review of Educational Research, 64, 1-35.

Coleman, J. (1988). Social capital in the creation of human capital. American Journal of Sociology, 94, 95-120. doi:10.1086/228943.

Cosier, R. A., \& Rechner, P. L. (1985). Inquiry method effects on performance in a simulated business environment. Organizational Behavior and Human Decision Processes, 36, 79-95. doi:10.1016/07495978(85)90021-4.

Curşeu, P. L., \& Schruijer, S. G. L. (2008). The effects of framing on inter-group negotiations. Group Decision and Negotiation, 17(4), 347-362. doi:10.1007/s10726-007-9098-2.

Curşeu, P. L., \& Schruijer, S. G. L. (2010). Does conflict shatter trust or does trust obliterate conflict? Revisiting the relationships between team diversity, conflict, and trust. Group Dynamics: Theory, Research, and Practice, 14, 66-79. doi:10.1037/a0017104.

Curşeu, P. L., Schruijer, S. G. L., \& Boroş, S. (2007). The effects of groups' variety and disparity on groups' cognitive complexity. Group Dynamics: Theory, Research, and Practice, 11, 187-206. doi:10.1037/ 1089-2699.11.3.187.

Curşeu, P. L., Schalk, M. J. D., \& Schruijer, S. G. L. (2010). The use of cognitive mapping in eliciting and evaluating group cognitions. Journal of Applied Social Psychology, 40, 1258-1291. doi:10.1111/j. 1559-1816.2010.00618.x.

Curşeu, P. L., Schruijer, S. G. L., \& Boroş, S. (in press). Socially rejected while cognitively successful: The impact of minority dissent on groups' cognitive complexity. British Journal of Social Psychology. doi: 10.1111/j.2044-8309.2011.02023.x. 
Davies, W. M. (2009). Groupwork as a form of assessment: Common problems and recommended solutions. Higher Education, 58, 563-584. doi:10.1007/s10734-009-9216-y.

Davies, W.M. (in press). Concept mapping, mind mapping and argument mapping: What are the differences and do they matter? Higher Education, doi:10.1007/s10734-010-9387-6.

Devine, D. J. (2002). A review and integration of classification systems relevant to teams in organizations. Group Dynamics: Theory Research and Practice, 6, 291-310. doi:10.1037/1089-2699.6.4.291.

Dillenbourg, P., Baker, M., Blaye, A., \& O'Malley, C. (1996). The evolution of research on collaborative learning. In E. Spada \& P. Reiman (Eds.), Learning in humans and machine: Towards an interdisciplinary learning science (pp. 189-211). UK: Elsevier.

Driver, M. J., \& Streufert, S. (1969). Integrative complexity: An approach to individuals and groups as information processing systems. Administrative Science Quarterly, 14, 272-285. doi:10.2307/2391105.

Gomez, A., Moreno, A., Pazos, J., \& Sierra-Alonso, A. (2000). Knowledge maps: An essential technique for conceptualization. Data \& Knowledge Engineering, 33, 169-190. doi:10.1016/S0169-023X(99)00050-6.

Graen, B. G., Hui, C., \& Taylor, E. A. (2006). Experience-based learning about LMX leadership and fairness in project teams: A dyadic directional approach. Academy of Management: Learning and Education, 5, $448-460$.

Haggis, T. (2009). What have we been thinking of? A critical overview of 40 years of student learning research in higher education. Studies in Higher Education, 34, 377-390. doi:10.1080/03075070902771903.

Hinsz, V. B., Vollrath, D. A., \& Tindale, R. S. (1997). The emerging conceptualization of groups as information processors. Psychological Bulletin, 121, 43-64. doi:10.1037/0033-2909.121.1.43.

Jehn, K. A. (1994). Enhancing effectiveness: An investigation of advantages and disadvantages of valuebased intragroup conflict. The International Journal of Conflict Management, 5, 223-238. doi: 10.1108/eb022744.

Jehn, K. A. (1995). A multimethod examination of the benefits and detriments of intragroup conflict. Administrative Science Quarterly, 40, 256-282. doi:10.2307/2393638.

Jehn, K. A., \& Mannix, E. A. (1997). The dynamic nature of conflict: A longitudinal study of intragroup conflict and group performance. Academy of Management Journal, 44, 238-251. doi:10.2307/3069453.

Kember, D. (2009). Nurturing generic capabilities through a teaching and learning environment which provides practice in their use. Higher Education, 57, 37-55. doi:10.1007/s10734-008-9131-7.

Lizzio, A., \& Wilson, K. (2006). Enhancing the effectiveness of self-managed learning groups: Understanding students' choices and concerns. Studies in Higher Education, 31, 689-703. doi:10.1080/ 03075070601004309.

Oh, H., Chung, M.-H., \& Labianca, G. (2004). Group social capital and group effectiveness: The role of informal socializing ties. Academy of Management Journal, 47, 860-875. doi:10.2307/20159627.

Parayitam, S., \& Dooley, R. S. (2009). The interplay between cognitive- and affective conflict and cognition- and affect-based trust in influencing decision outcomes. Journal of Business Research, 62, 789-796. doi:10.1016/j.jbusres.2008.02.006.

Pinkley, R. I. (1990). Dimensions of conflict frame: Disputants interpretations of conflict. Journal of Applied Psychology, 75, 775-822. doi:10.1037/0021-9010.75.2.117.

Portes, A., \& Sensenbrenner, J. (1993). Embeddedness and immigration: Notes on the social determinants of economic action. The American Journal of Sociology, 98, 1320-1350. doi:10.1086/230191.

Reagans, R., Zuckerman, E., \& McEvily, B. (2004). How to make the team: Social networks versus demographic as criteria for designing effective teams. Administrative Science Quarterly, 49, 101-133.

Scott, J. (1991). Social Network Analysis: A Handbook. London: Sage Publications.

Simons, T. L., \& Peterson, R. S. (2000). Task conflict and relationship conflict in top management teams: The pivotal role of intragroup trust. Journal of Applied Psychology, 85, 101-111. doi:10.1037/ 0021-9010.85.1.102.

Springer, L., Stanne, M. E., \& Donovan, S. S. (1999). Effects of small-group learning on undergraduates in science, mathematics, engineering, and technology: A meta-analysis. Review of Educational Research, 69, 21-51.

Steiner, I. D. (1972). Group processes and productivity. New York: Academic Press.

Tomarken, J., \& Waller, N. G. (2005). Structural equation modeling: Strengths, limitations and misconceptions. Annual Review of Clinical Psychology, 1, 31-65. doi:10.1146/annurev.clinpsy.1.102803. 144239.

Widman, K. F., \& Thomson, J. (2003). On specifying the null model for incremental fit indices in structural equation modeling. Psychological Methods, 8, 16-37. doi:10.1037/1082-989X.8.1.16. 